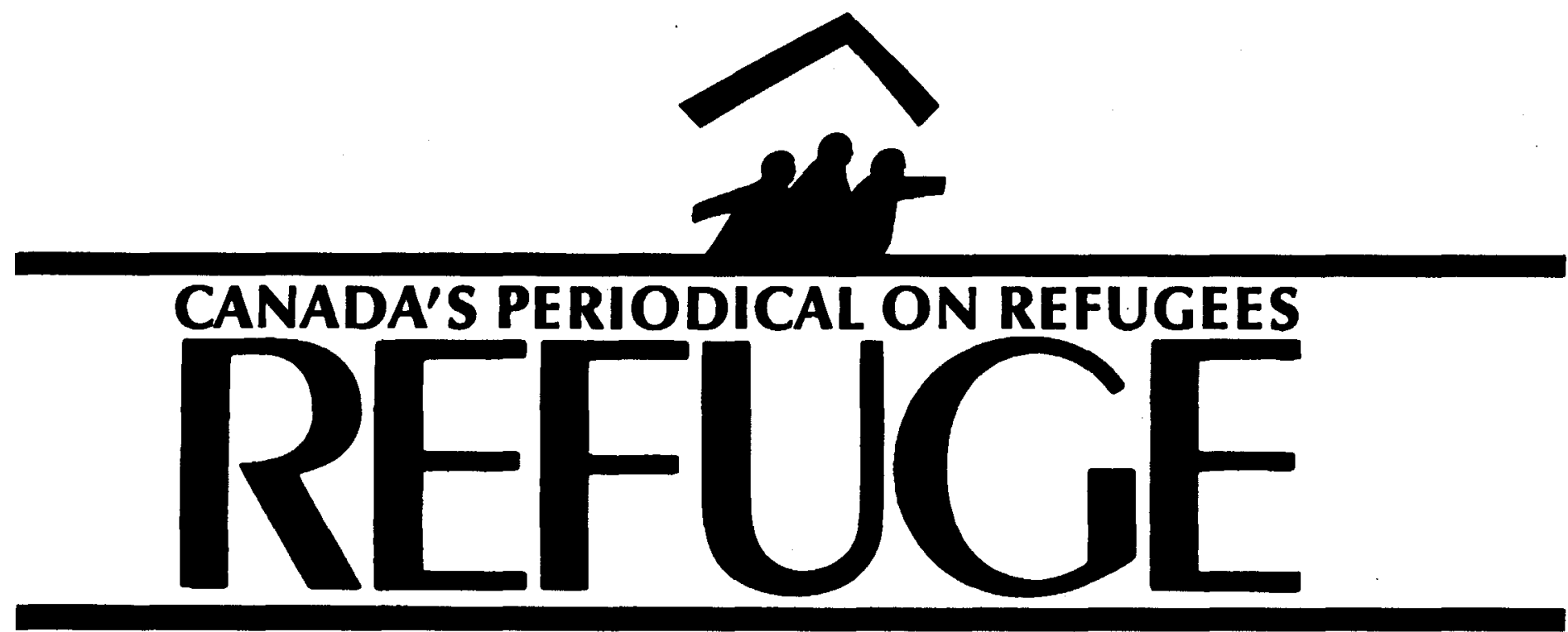

Vol. $13 \cdot$ No. 1

April 1993

\title{
Canadian Policy, Global Apartheid and African Development
}

Canada no longer practises racial discrimination towards African migrants and refugees. Growing numbers of refugees from Africa have been accepted into Canada as refugee claimants. Nevertheless, in addition to data supporting these two conclusions, Yohannes Gebresellasie offers a plethora of data to show that Canada discourages the resettlement of African refugees in Canada and would prefer that they settle elsewhere. Relatively few refugees (compared to the actual number in Africa and elsewhere) are able to make a refugee claim in Canada and fewer still are accepted.

Gebresellasie's article offers further evidence to support Anthony Richmond's thesis that the West is moving towards a nonexodus approach to immigrants and refugees from the Third World. Richmond contends that there is a deliberate effort to recreate apartheid on a global scale. He also predicts it will fail.

Gebresellasie also briefly discusses the aid provided for resolving conflicts that produce refugees and for assisting in refugee settlement and repatriation and concludes it too is inadequate. Mohamed Ali Arkow looks at the possibility of aid as a way of dealing with refugee-producing conflicts that are products of rapidly increasing population, environmental degradation, inappropriate technologies and consumer demand for new products produced by the West. Arkow advocates a system of appropriate technology transfers rather than more loans, which would impoverish African countries even further.

But what assurance do we have that these technology transfers will be beneficial? In any case, I have just returned from an OECD meeting in Madrid on migration and development; evidence suggested that in the short and medium term, development exacerbates rather than stems migration flows. Will the resulting response be global apartheid as
Richmond predicts, fears and deplores, or is this too pessimistic a conclusion about the inadequate efforts to cope with conflicts and refugees?

This is futurology about probable outcomes of different courses of action. But values as well as forces also have their effects. We must understand the forces at work predisposing certain outcomes. We must also decide our normative priorities in dealing with these forces. Norms can influence the weight and effect of various forces. Given our best understanding of the factors at work, it is our values and decisions that will give those forces a direction.

Howard Adelman

\section{Contents:}

Canada's Response to Black African Immigrants Yohannes Gebresellasie.

Open and Closed Borders:

Is the New World Order Creating a System of Global Apartheid?

Anthony H. Richmond

Development in a Fragile Environment: The Case of Somalia Mohamed Ali Arkow

Book Review: Nations of Immigrants: Australia, the United States, and International Migration Nobuaki Suyama 